\title{
Ocorrência de bactérias diazotróficas associadas a cultivares de sorgo forrageiro
}

\author{
Occurrence of diazotrophic bacteria associated with forage sorghum cultivars
}

\author{
Clarissa Bergamaschi ${ }^{\mathrm{I}}$ Luiz Fernando Würdig Roesch ${ }^{\mathrm{I}}$ Patrícia Dörr de Quadros ${ }^{\mathrm{I}}$ \\ Flávio Anastácio de Oliveira Camargo ${ }^{\mathrm{I}}$
}

\section{RESUMO}

O presente estudo objetivou avaliar a ocorrência de bactérias diazotróficas associadas ao sorgo, selecionar cultivares eficientes na associação com bactérias diazotróficas $e$ identificar os isolados mais eficientes em fixar nitrogênio atmosférico $\left(\mathrm{N}_{2}\right)$ e produzir ácido indol-acético (AIA). Utilizaram-se 14 cultivares de sorgo forrageiro em vasos, com dois níveis de N: 0 e $130 \mathrm{~kg} \mathrm{ha}^{-1}$ de N. A seleção de cultivares foi baseada na associação com bactérias diazotróficas e na eficiência de absorção de nitrogênio das cultivares. Para o isolamento das bactérias, foram utilizados diferentes meios de enriquecimento semi-sólido e, após o isolamento, foram quantificadas a produção de AIA e a quantidade de N2 fixada pelos isolados. A ocorrência de bactérias diazotróficas foi constatada em todas as cultivares avaliados sendo que a distribuição das bactérias isoladas foi influenciada pelo genótipo da planta. Todos os isolados foram aptos em fixar $\mathrm{N}_{2}$ e produzir AIA in vitro.

Palavras-chave: bactérias fixadoras de nitrogênio, produção de ácido indol-acético.

\section{ABSTRACT}

The present study aimed to evaluate the occurrence of diazotrophic bacterial associated with sorghum plants, to select efficient sorghum cultivars associated with diazotrophic bacterial, as well as to identify isolates efficient on nitrogen fixation $\left(\mathrm{N}_{2}\right)$ and indole acetic acid (IAA) production. Fourteen forage sorghum cultivars were cropped in jars under two levels of nitrogen fertilization: 0 and $130 \mathrm{~kg} \mathrm{ha}^{-1}$ of $N$. The selection of sorghum cultivars was based on the association with diazothophic bacterial and on the efficiency of nitrogen absorption. Semi-solid enrichment medium was used for the isolation of the diazotrophic bacterial. The occurrence of diazotrophics was verified in all cultivars of sorghum evaluated and, the distribution of the isolates was affected by the plant genotype. All the isolates were able to fix $\mathrm{N}_{2}$ and to produce IAA in vitro.
Key words: nitrogen fixing bacteria, indole acetic acid production.

\section{INTRODUÇÃO}

No Brasil, os produtores de sorgo costumam ter grandes gastos com fertilizantes nitrogenados todos os anos. Além do alto custo, a adubação nitrogenada pode ainda provocar danos ao ambiente, podendo afetar a sustentabilidade do agroecossistema. No solo, destaca-se a presença de bactérias diazotróficas, que são microrganismos que realizam a conversão enzimática do nitrogênio gasoso em amônia. Além da fixação biológica de nitrogênio (FBN), alguns desses microrganismos também produzem substâncias promotoras de crescimento de plantas (PCPs). Com isto, reduzem-se custos com adubação nitrogenada e minimizam-se os danos ao ambiente.

Pesquisas demonstraram que a inoculação de bactérias diazotróficas em plantas de sorgo promove respostas significativas. Inoculando o gênero Azoarcus em plantas de sorgo para avaliar a FBN, STEIN et al. (1997) observaram considerável atividade de fixação de nitrogênio, estimada em $10,7 \%$ do $\mathrm{N}$ da parte aérea e $2 \%$ do $\mathrm{N}$ da raiz. Contudo, esse potencial de fixação depende da interação das bactérias com o genótipo da planta, dos fatores abióticos do meio e da competitividade com os demais microrganismos do local. Portanto, a interação bactéria-gramínea, em termos de potencialidade agronômica como fixadoras de $\mathrm{N}_{2}$

\footnotetext{
IDepartamento de Ciência do Solo, Universidade Federal do Rio Grande do Sul (UFRGS). Av. Bento Gonçalves, 7712, 91540-000, Porto Alegre, RS, Brasil. E-mail: fcamargo@ufrgs.br.
} 
ou como produtoras de PCPs, depende desse grau de associação.

Estudos demonstraram que o genótipo da planta pode influenciar o tamanho e a composição da comunidade microbiana através dos exudatos liberados pelas raízes, que exercem papel chave no estímulo seletivo dos microrganismos. BODDEY et al. (1991) comprovaram que uma mesma bactéria pode ter diferentes graus de atividades da nitrogenase, quando inoculada em diferentes genótipos de sorgo, demonstrando que há uma estreita associação entre planta e bactéria.

Para desenvolver práticas viáveis ao aproveitamento desses microrganismos na cultura de sorgo, é necessário avaliar diferentes genótipos de sorgo em relação à resposta à adubação nitrogenada e à associação com bactérias diazotróficas específicas. Deste modo, o presente estudo objetivou avaliar a ocorrência de bactérias diazotróficas associadas à cultivares de sorgo atualmente utilizadas no Rio Grande do Sul, selecionar as cultivares mais eficientes na associação com bactérias diazotróficas, assim como identificar os isolados mais eficientes em fixar nitrogênio e produzir ácido indol-acético.

\section{MATERIAL E MÉTODOS}

O experimento foi conduzido em vasos, ao ar livre, durante 59 dias. Os vasos continham solo proveniente do horizonte superficial de um Argissolo Vermelho-Amarelo distrófico arênico (EMBRAPA, 1999). Este solo apresentava as seguintes características: $\mathrm{pH}\left(\mathrm{H}_{2} \mathrm{O}\right) 5,0,130 \mathrm{~g} \mathrm{~kg}^{-1}$ de argila, $5 \mathrm{~g} \mathrm{~kg}$ ${ }^{1}$ de matéria orgânica, 2,9mg L ${ }^{-1}$ de $\mathrm{P}, 19 \mathrm{mg} \mathrm{L}^{-1}$ de K, 0,2 $\mathrm{cmol}_{\mathrm{c}} \mathrm{L}^{-1}$ de Al trocável, 0,5 $\mathrm{cmol}_{\mathrm{c}} \mathrm{L}^{-1}$ de Ca trocável, 0,3 $\mathrm{cmol}_{\mathrm{C}} \mathrm{L}^{-1}$ de $\mathrm{Mg}$ trocável, 1,6 $\mathrm{cmol}_{\mathrm{c}} \mathrm{L}^{-1}$ de $\mathrm{H}+\mathrm{Al}$, 2,4 $\mathrm{cmol}_{\mathrm{C}} \mathrm{L}^{-1}$ de CTC e $35 \%$ de saturação por bases, segundo metodologia descrita em TEDESCO et al. (1995).

A adubação foi baseada na análise físicoquímica do solo e na Recomendação de Adubação e Calagem para o Rio Grande do Sul e Santa Catarina (CAFS-RS/SC, 2004). Aplicaram-se 86,4mg L ${ }^{-1}$ de $\mathrm{P}_{2} \mathrm{O}_{5}$ e $194,4 \mathrm{mg} \mathrm{L}^{-1}$ de $\mathrm{K}_{2} \mathrm{O}$ por vaso na forma de solução nutritiva de $\mathrm{KH}_{2} \mathrm{PO}_{4}$, correspondendo a $48 \mathrm{~kg}$ ha- 1 de fósforo e $108 \mathrm{~kg} \mathrm{ha}^{-1}$ de potássio. Para o tratamento com nitrogênio, foram aplicados 40, 76 e 76mg de $\mathrm{N}$ por vaso na semeadura, aos sete e 21 dias após a emergência das plantas, respectivamente. O nitrogênio foi aplicado sob a forma de solução nutritiva, correspondendo a um total de $130 \mathrm{~kg} \mathrm{ha}^{-1}$ de nitrogênio.

Aos 53 dias após a emergência, foi efetuada a colheita da parte aérea das plantas de todos os tratamentos. A matéria seca da parte aérea das cultivares de sorgo foi analisada quanto ao conteúdo de nitrogênio total determinado a partir da digestão sulfúrica do tecido vegetal (TEDESCO et al., 1995). A seleção de cultivares de sorgo foi baseada na associação com bactérias diazotróficas e na eficiência de absorção de nitrogênio. A associação com bactérias diazotróficas foi estimada com base na diversidade de gêneros bacterianos isolados das cultivares de sorgo. A eficiência de absorção de nitrogênio foi calculada pela razão entre a diferença na quantidade de $\mathrm{N}$ das plantas com e sem adubação nitrogenada e a quantidade de $\mathrm{N}$ mineral aplicado nos tratamentos que receberam esse nutriente.

O isolamento de bactérias diazotróficas foi realizado segundo DÖBEREINER et al. (1995), em amostras de raízes das plantas sem aplicação de nitrogênio. Amostras de $10 \mathrm{~g}$ de raízes foram trituradas com solução salina e feitas diluições seriadas de $10^{-2} \mathrm{e}$ $10^{-3}$. As amostras foram inoculadas nos meios de enriquecimento semi-sólidos NFb, JNFb e JMV, utilizados para o isolamento de Azospirillum, Herbaspirillum e Burkholderia, respectivamente. Os meios de cultura foram incubados a $28^{\circ} \mathrm{C}$ até a formação de película característica (cerca de sete dias). Após a formação de película, parte dela foi transferida para placas contendo meio sólido de enriquecimento para cada microrganismo a ser isolado, acrescido de $20 \mathrm{mg}$ de extrato de levedura. Para a purificação, as colônias formadas no meio sólido foram novamente transferidas para meios de cultura semi-sólidos e, após isso, transferidas para placas de Petri contendo meio ÁgarBatata (BALDANI \& DÖBEREINER, 1980). Uma vez isoladas, as colônias foram armazenadas em microtubos contendo uma mistura de leite em pó + glicerol e congeladas a $-18^{\circ} \mathrm{C}$. Para identificar o provável gênero bacteriano, observaram-se características morfológicas das colônias em placas de Petri, tais como forma, bordos, coloração, textura e mudança de $\mathrm{pH}$, em dois diferentes meios de cultura (DÖBEREINER et al., 1995).

Para quantificar o nitrogênio total fixado pelos isolados, alíquotas de $70 \mu \mathrm{L}$ da mistura de leite + glicerol foram inoculados em tubos contendo caldo nutritivo Dygs e incubadas sob agitação de $140 \mathrm{~g}$ por 24h. Após isso, o número de células foi padronizado em espectrofotômetro, em densidade ótica de 0,2 , com comprimento de onda de 600nm. Uma vez padronizadas as amostras, alíquotas de $600 \mu \mathrm{L}$ foram transferidas para meios de cultura semi-sólidos (três repetições) e incubadas em estufa a $28^{\circ} \mathrm{C}$ por $72 \mathrm{~h}$. Como controle, foi utilizado meio de cultura semi-sólido esterilizado não-inoculado. Após a incubação, alíquotas de 500 $\mu$ de cada amostra foram tomadas para a quantificação 
de proteínas, segundo BRADFORD (1976). Como padrão de comparação entre isolados, utilizou-se a estirpe Azospirillum brasilense Sp7 (ATCC 29145). O nitrogênio total foi quantificado após digestão sulfúrica e destilação com $\mathrm{NaOH} 10 \mathrm{~mol} \mathrm{~L}^{-1}$ (TEDESCO et al., 1995).

Para verificar a produção de ácido indolacético (AIA), 70 $\mu \mathrm{L}$ da mistura do leite + glicerol foram inoculados em tubos contendo caldo nutritivo Dygs e incubados sob agitação de $140 \mathrm{~g}$ por $24 \mathrm{~h}$. Após isso, o número de células foi padronizado em espectrofotômetro a uma densidade ótica de 0,3 , a um comprimento de onda de 600nm. Erlenmeyers contendo $25 \mathrm{~mL}$ de caldo nutritivo Dygs foram inoculados com $600 \mu \mathrm{L}$ das culturas. Os meios foram incubados sob agitação de $140 \mathrm{~g}$, a $30^{\circ} \mathrm{C}$, por $72 \mathrm{~h}$. Foi utilizada como padrão a estirpe Azospirillum brasilense Sp7 (ATCC 29145). Após a incubação, as amostras foram centrifugadas a $8.000 \mathrm{~g}$ por 15 minutos e, em seguida, $3 \mathrm{~mL}$ do sobrenadante foram adicionados a $2 \mathrm{~mL}$ do reagente de Salkowski $\left(2 \mathrm{~mL}\right.$ de $\mathrm{FeCl}_{3} 0,5 \mathrm{~mol} \mathrm{~L}^{-1}+98 \mathrm{~mL}$ de $\mathrm{HClO}_{4} 35 \%$ ). Após 30 minutos, a intensidade da cor foi mensurada em espectrofotômetro a 550nm. A curva padrão continha o caldo nutritivo esterilizado e quantidades conhecidas de AIA. A quantidade de AIA produzida foi calculada através da equação $(\mathrm{y}=0,0188 \mathrm{x}$ $+0,0003$; onde $\mathrm{y}=$ [AIA] e $\mathrm{x}=$ intensidade da cor mensurada em espectrofotômetro a 550nm), cujos limites de detecção foram 1,0 a $50 \mu \mathrm{g} \mathrm{mL}^{-1}$ de AIA. Foram tomados $500 \mu \mathrm{L}$ de cada amostra para quantificar proteínas, segundo metodologia de BRADFORD (1976).

Os resultados obtidos foram submetidos à análise de variância e ao teste de Scott-Knott para comparação de médias.

\section{RESULTADOS E DISCUSSÃO}

Foram obtidos 76 isolados de três meios de enriquecimento: NFb, JNFb e JMV. Uma matriz binária foi elaborada a partir de características das colônias dos isolados. A partir destas características, verificouse que, de quatro grupos formados, três apresentaram $100 \%$ de similaridade com as estirpes padrão Herbaspirillum seropedicae Z67 (ATCC 35892), Azospirillum brasilense Sp7 (ATCC 29145) e Burkholderia tropica Ppe8 (ATCC BAA-831) (Figura 1).

$\mathrm{O}$ isolamento de bactérias mostrou que as 14 cultivares de sorgo forrageiro testadas foram aptas na associação com bactérias diazotróficas e, de acordo com a análise de similaridade, os isolados provavelmente pertencem aos gêneros Azospirillum, Herbaspirillum e Burkholderia. Estes resultados estão de acordo com pesquisas anteriores, que demonstraram a presença destes gêneros de bactérias em plantas de sorgo (BALDANI et al., 1986; CHIARINI et al.,1998; BASHAN et al., 2004).

Considerando a presença de bactérias diazotróficas nqas 14 cultivares de sorgo analisadas, verificou-se que todas as cultivares estiveram associados a bactérias diazotróficas (Tabela 1). “Fepagro RS 18”, “Past 76” e “BR 601” apresentaram a maior diversidade, de acordo com os índices de Shannon-Weaver e Simpson (Tabela 1). Os resultados indicam que o genótipo da planta exerce efeitos diferenciais na colonização por estas bactérias, o que pode ser devido à composição química dos exudatos liberados pelas plantas, a qual pode variar entre genótipos (KIPE-NOLT et al., 1985). Segundo GRAYSTON et al. (1998), a variedade destes compostos liberados influencia a diversidade de microrganismos presentes na rizosfera. Assim sendo, a variação na diversidade de organismos isolados nas diferentes cultivares de sorgo pode ser explicada pela especificidade que ocorre entre planta e bactéria.

A produção de matéria seca e o teor de nitrogênio total das cultivares de sorgo aumentaram com a adubação nitrogenada (Tabela 2). As maiores produções de matéria seca foram observadas nas cultivares “BR 610”, “1 F 305”, "BRS 800” e “Fepagro 19 ”, quando foram aplicados $130 \mathrm{~kg} \mathrm{ha}^{-1}$ de N. Quanto ao nitrogênio total no tecido das plantas, as cultivares “BRS 800”, “1 F 305”, “BR 610”, “Fepagro 19” e “855 F” foram as que apresentaram os maiores valores, com aplicação de nitrogênio (Tabela 2). A eficiência relativa de aproveitamento do nitrogênio aplicado variou entre cultivares (Tabela 2). Tal resposta pode ser atribuída a diferenças genéticas das cultivares (FERNANDES et al., 1991). Nos tratamentos em que não foi aplicado nitrogênio mineral, verificou-se uma baixa produção de matéria seca e acúmulo de $\mathrm{N}$ pelas cultivares testadas. Tais resultados podem indicar que a população de bactérias diazotróficas naturalmente associada a plantas de sorgo apresentou uma baixa fixação biológica de nitrogênio, insuficiente para refletir em aumento de matéria seca e nitrogênio total no tecido das plantas.

Embora não se tenha observado grandes incrementos na produção de matéria seca e no acúmulo de $\mathrm{N}$ no tecido das plantas quando não foi aplicado nitrogênio, de acordo com os resultados obtidos, as cultivares "Fepagro RS 18”, "Past 76” e "BR 601" mostraram-se promissoras para futuros estudos, considerando sua aparente eficiência na associação com bactérias diazotróficas. Para essas cultivares, observou-se elevada diversidade de bactérias diazotróficas associadas, nas quais foram isoladas bactérias dos meios de cultura JMV, JNFb e NFb. 


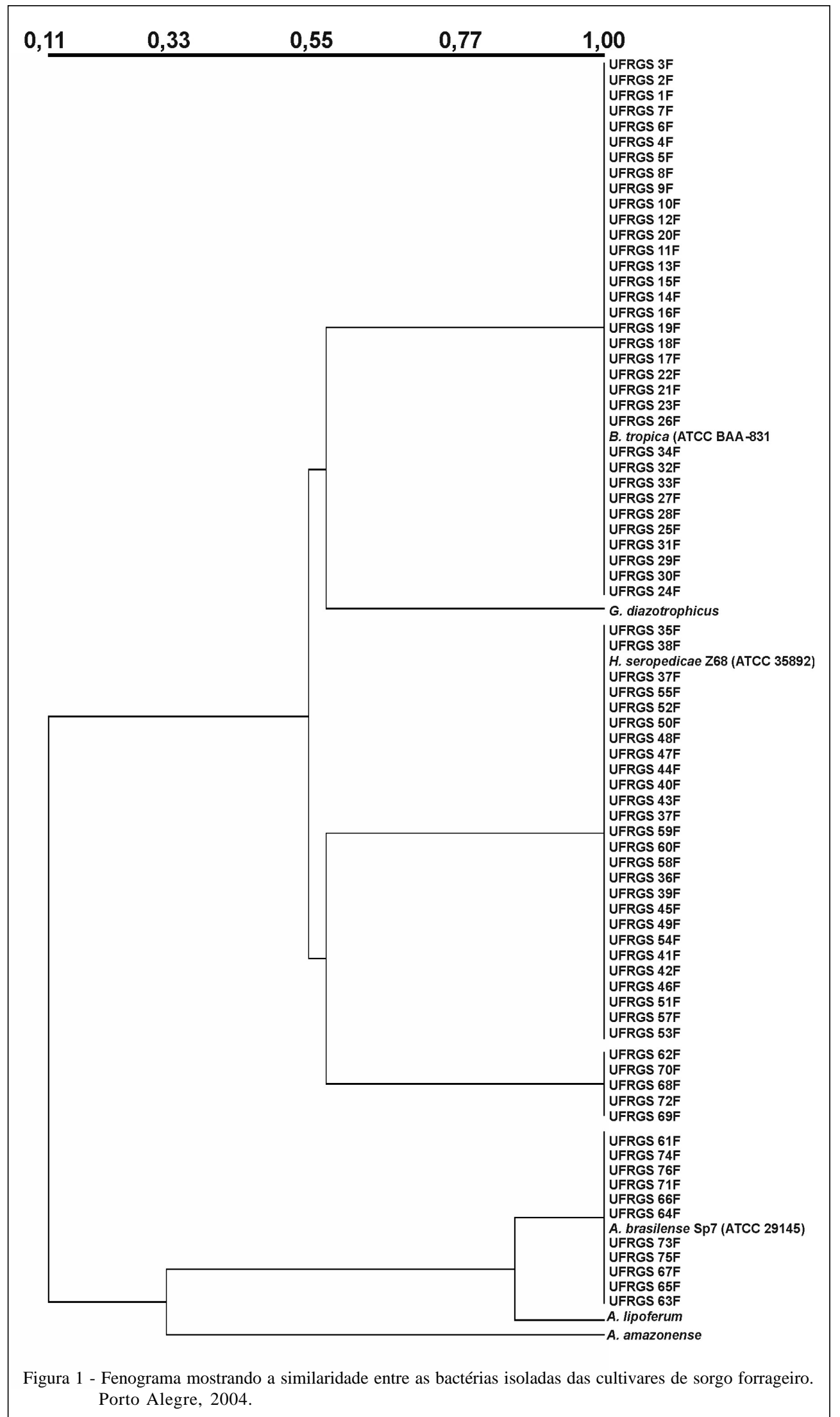

Ciência Rural, v.37, n.3, mai-jun, 2007. 
Tabela 1 - Índices de diversidade entre comunidades isoladas das cultivares de sorgo forrageiro do tratamento sem nitrogênio. Porto Alegre, 2004.

\begin{tabular}{|c|c|c|c|c|c|}
\hline \multirow[t]{2}{*}{ Cultivar } & \multicolumn{5}{|c|}{ Índices de diversidade } \\
\hline & I & $\mathrm{S}$ & $1-D$ & $H$ & $E$ \\
\hline 1 F 305 & 1 & 1 & 0 & 0 & 0 \\
\hline Fepagro RS 12 & 5 & 2 & 0,48 & 0,67 & 0,97 \\
\hline Fepagro RS 17 & 7 & 2 & 0,41 & 0,60 & 0,86 \\
\hline Fepagro RS 18 & 7 & 3 & 0,65 & 1,08 & 0,98 \\
\hline Fepagro 19 & 7 & 2 & 0,41 & 0,60 & 0,86 \\
\hline Past 49 C & 3 & 2 & 0,44 & 0,64 & 0,92 \\
\hline Past 76 & 6 & 3 & 0,61 & 1,01 & 0,92 \\
\hline Past 10 & 8 & 2 & 0,46 & 0,66 & 0,95 \\
\hline BR 610 & 6 & 2 & 0,44 & 0,64 & 0,92 \\
\hline BR 506 & 4 & 2 & 0,37 & 0,56 & 0,81 \\
\hline Fepagro RS 11 & 1 & 1 & 0 & 0 & 0 \\
\hline BRS 800 & 4 & 2 & 0,5 & 0,69 & 1,00 \\
\hline BR 601 & 9 & 3 & 0,59 & 0,96 & 0,88 \\
\hline $855 \mathrm{~F}$ & 8 & 2 & 0,5 & 0,69 & 1,00 \\
\hline
\end{tabular}

I: número de isolados; S: número de gêneros; $1-D$ : índice de diversidade de Simpson; $H$ : Shannon-Weaver; $E$ : Equitabilidade.

Os resultados da quantificação do nitrogênio atmosférico fixado pelas bactérias isoladas das cultivares de sorgo forrageiro (Tabela 3) variaram de 3,78 $\mu \mathrm{g} \mathrm{N} \mathrm{mg} \mathrm{proteína}{ }^{-1}$ dia $^{-1}$ (isolado UFRGS21F) a $229,72 \mu \mathrm{g} \mathrm{N}$ mg proteína ${ }^{-1}$ dia $^{-1}$ (isolado UFRGS62F). As bactérias UFRGS62F, UFRGS60F e UFRGS55F foram as que mais fixaram $\mathrm{N}_{2}$ in vitro.

Os valores da quantificação de AIA das

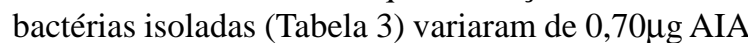

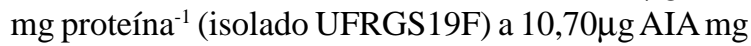

Tabela 2 - Matéria seca e quantidade de N acumulado na parte aérea das plantas de sorgo forrageiro avaliadas aos 53 dias após a emergência. Porto Alegre, 2004. (Médias de duas plantas por vaso e três repetições).

\begin{tabular}{|c|c|c|c|c|c|}
\hline \multirow{4}{*}{ Cultivar } & \multicolumn{2}{|c|}{ Matéria seca } & \multicolumn{2}{|c|}{ Nitrogênio total } & \multirow{4}{*}{$\begin{array}{l}\text { Eficiência relativa de } \\
\text { aproveitamento do } \mathrm{N}\end{array}$} \\
\hline & \multicolumn{4}{|c|}{ Adubação nitrogenada (kg de $\mathrm{N} \mathrm{ha}^{-1}$ ) } & \\
\hline & 0 & 130 & 0 & 130 & \\
\hline & \multicolumn{2}{|c|}{--------- g planta ${ }^{-1}$--------- } & \multicolumn{2}{|c|}{------ mg N planta ${ }^{-1}$------ } & \\
\hline 1 F 305 & $1,08 \mathrm{~A} \mathrm{~b}$ & $8,49 \mathrm{~A}$ a & 4,51 B b & $54,18 \mathrm{~A} \mathrm{a}$ & 25,87 \\
\hline Fepagro RS 12 & 0,98 A b & $5,73 \mathrm{~B}$ a & 4,51 B b & $33,57 \mathrm{C} \mathrm{a}$ & 14,19 \\
\hline Fepagro RS 17 & $0,70 \mathrm{~A} \mathrm{~b}$ & 6,93 B а & $4,16 \mathrm{~B} \mathrm{~b}$ & $48,34 \mathrm{~B} \mathrm{a}$ & 22,66 \\
\hline Fepagro RS 18 & $0,97 \mathrm{~A} \mathrm{~b}$ & $6,79 \mathrm{~B} \mathrm{a}$ & $5,40 \mathrm{~A} \mathrm{~b}$ & $50,49 \mathrm{~B} \mathrm{a}$ & 23,12 \\
\hline Fepagro 19 & 0,83 A b & 7,45 A a & $4,25 \mathrm{~B} \mathrm{~b}$ & $52,44 \mathrm{~A} \mathrm{a}$ & 24,71 \\
\hline Past $49 \mathrm{C}$ & $1,12 \mathrm{~A} \mathrm{~b}$ & 6,97 B a & 5,76 A b & 50,18 B a & 22,78 \\
\hline Past 76 & 0,66 A b & 5,99 B а & 5,51 A b & $46,24 \mathrm{~B} \mathrm{a}$ & 20,88 \\
\hline Past 10 & $0,92 \mathrm{~A} b$ & $6,00 \mathrm{~B}$ a & $5,18 \mathrm{~A} \mathrm{~b}$ & $47,08 \mathrm{~B} \mathrm{a}$ & 21,48 \\
\hline BR 610 & $0,92 \mathrm{~A} b$ & $8,54 \mathrm{~A} \mathrm{a}$ & $5,27 \mathrm{~A} \mathrm{~b}$ & $53,67 \mathrm{~A} \mathrm{a}$ & 24,81 \\
\hline BR 506 & $1,07 \mathrm{~A} \mathrm{~b}$ & $6,47 \mathrm{~B} \mathrm{a}$ & $5,54 \mathrm{~A} \mathrm{~b}$ & $46,15 \mathrm{~B} \mathrm{a}$ & 21,06 \\
\hline Fepagro RS 11 & $1,00 \mathrm{~A} \mathrm{~b}$ & $6,05 \mathrm{~B} \mathrm{a}$ & $5,64 \mathrm{~A} \mathrm{~b}$ & 47,39 B а & 21,41 \\
\hline BRS 800 & $1,00 \mathrm{~A} \mathrm{~b}$ & $7,72 \mathrm{~A} \mathrm{a}$ & $4,56 \mathrm{~B}$ b & $55,08 \mathrm{~A} \mathrm{a}$ & 25,90 \\
\hline BR 601 & $0,82 \mathrm{~A} \mathrm{~b}$ & $6,31 \mathrm{~B} \mathrm{a}$ & 4,82 B b & $49,22 \mathrm{~B} \mathrm{a}$ & 22,76 \\
\hline $855 \mathrm{~F}$ & $1,07 \mathrm{~A} \mathrm{~b}$ & 4,39 B a & 4,32 B b & $51,62 \mathrm{~A} \mathrm{a}$ & 24,25 \\
\hline CV (\%) & 19,56 & 11,27 & 9,91 & 5,86 & \\
\hline
\end{tabular}

Médias seguidas da mesma letra maiúscula na coluna e minúscula na linha não diferem entre si pelo Teste de Scott-Knott a 5\% de probabilidade de erro.

Ciência Rural, v.37, n.3, mai-jun, 2007. 
Tabela 3 - N fixado e produção de AIA das bactérias isoladas das cultivares de sorgo.

\begin{tabular}{|c|c|c|c|c|c|}
\hline \multirow[t]{2}{*}{ Isolado } & $\mathrm{N}$ fixado & AIA & Isolado & $\mathrm{N}$ fixado & AIA \\
\hline & $\begin{array}{c}\mu \mathrm{g} N \mathrm{Ng} \\
\text { proteína }^{-1} \mathrm{dia}^{-1}\end{array}$ & $\begin{array}{l}\mu \mathrm{g} \text { AIA mg } \\
\text { proteína }^{-1}\end{array}$ & & $\begin{array}{c}\mu \mathrm{g} \mathrm{N} \mathrm{mg} \\
\text { proteína }^{-1} \mathrm{dia}^{-1}\end{array}$ & $\begin{array}{l}\mu \mathrm{g} \text { AIA mg } \\
\text { proteína }^{-1}\end{array}$ \\
\hline UFRGS 1F & $11,60 \mathrm{~h}$ & $5,13 d$ & UFRGS40F & $56,07 \mathrm{f}$ & $3,35 \mathrm{e}$ \\
\hline UFRGS 2F & $26,01 \mathrm{~g}$ & $3,41 \mathrm{e}$ & UFRGS41F & $87,92 \mathrm{e}$ & $5,77 \mathrm{c}$ \\
\hline UFRGS 3F & $16,63 \mathrm{~h}$ & $7,97 \mathrm{~b}$ & UFRGS42F & $57,79 \mathrm{f}$ & $4,46 \mathrm{~d}$ \\
\hline UFRGS 4F & $20,54 \mathrm{~h}$ & $1,87 f$ & UFRGS43F & $56,07 \mathrm{f}$ & $4,46 \mathrm{~d}$ \\
\hline UFRGS 5F & $43,83 \mathrm{~g}$ & $3,02 \mathrm{e}$ & UFRGS44F & 87,92 e & $5,87 \mathrm{c}$ \\
\hline UFRGS 6F & $14,83 \mathrm{~h}$ & $1,80 \mathrm{f}$ & UFRGS45F & $57,79 \mathrm{f}$ & $7,65 \mathrm{c}$ \\
\hline UFRGS 7F & $27,60 \mathrm{~g}$ & $4,95 d$ & UFRGS46F & $56,07 \mathrm{f}$ & 9,19 a \\
\hline UFRGS 8F & $28,48 \mathrm{~g}$ & $4,95 d$ & UFRGS47F & $87,92 \mathrm{e}$ & 9,30 a \\
\hline UFRGS 9F & $14,24 \mathrm{~h}$ & $4,90 \mathrm{~d}$ & UFRGS48F & $57,79 \mathrm{f}$ & 9,30 a \\
\hline UFRGS 10F & $8,43 \mathrm{~h}$ & $7,26 \mathrm{c}$ & UFRGS49F & $56,07 \mathrm{f}$ & $5,61 \mathrm{c}$ \\
\hline UFRGS 11F & $43,69 \mathrm{~g}$ & $6,90 \mathrm{c}$ & UFRGS50F & 87,92 e & $5,69 \mathrm{c}$ \\
\hline UFRGS $12 \mathrm{~F}$ & $16,76 \mathrm{~h}$ & $3,03 e$ & UFRGS51F & $80,20 \mathrm{e}$ & $4,77 \mathrm{~d}$ \\
\hline UFRGS $13 F$ & $12,68 \mathrm{~h}$ & $3,03 e$ & UFRGS52F & $67,05 \mathrm{f}$ & $2,35 \mathrm{f}$ \\
\hline UFRGS 14F & $20,94 \mathrm{~g}$ & $3,02 \mathrm{e}$ & UFRGS53F & $49,02 \mathrm{f}$ & $7,86 \mathrm{~b}$ \\
\hline UFRGS 15F & $16,85 \mathrm{~h}$ & $6,16 c$ & UFRGS54F & 83,18 e & $5,24 \mathrm{~d}$ \\
\hline UFRGS 16F & $17,77 \mathrm{~h}$ & $9,04 a$ & UFRGS55F & 223,39 a & $6,94 \mathrm{c}$ \\
\hline UFRGS 17F & $39,15 \mathrm{~g}$ & $6,50 \mathrm{c}$ & UFRGS56F & $196,93 \mathrm{~b}$ & 8,97 a \\
\hline UFRGS 18F & $18,90 \mathrm{~h}$ & $4,18 \mathrm{~d}$ & UFRGS57F & 82,55 e & $1,56 \mathrm{f}$ \\
\hline UFRGS 19F & $11,20 \mathrm{~h}$ & $0,70 \mathrm{f}$ & UFRGS58F & $159,30 \mathrm{c}$ & $7,16 \mathrm{c}$ \\
\hline UFRGS 20F & $25,59 \mathrm{~g}$ & $4,43 d$ & UFRGS59 & $194,89 \mathrm{~b}$ & $7,16 \mathrm{c}$ \\
\hline UFRGS 21F & $3,78 \mathrm{~h}$ & $3,02 \mathrm{e}$ & UFRGS60F & $227,64 \mathrm{a}$ & $7,16 \mathrm{c}$ \\
\hline UFRGS 22F & $16,58 \mathrm{~h}$ & $3,02 \mathrm{e}$ & UFRGS61F & $67,47 \mathrm{f}$ & $5,99 \mathrm{c}$ \\
\hline UFRGS 23F & $19,40 \mathrm{~h}$ & $4,43 d$ & UFRGS62F & 229,72 a & 3,36 e \\
\hline UFRGS 24F & $20,54 \mathrm{~h}$ & $4,36 \mathrm{~d}$ & UFRGS63F & $66,27 \mathrm{f}$ & $6,52 \mathrm{c}$ \\
\hline UFRGS 25F & $32,45 \mathrm{~g}$ & $3,61 \mathrm{e}$ & UFRGS64F & $73,37 \mathrm{f}$ & $8,00 \mathrm{~b}$ \\
\hline UFRGS 26F & $11,36 \mathrm{~h}$ & $4,69 \mathrm{~d}$ & UFRGS65F & $55,04 \mathrm{f}$ & $6,27 \mathrm{c}$ \\
\hline UFRGS 27F & $27,03 \mathrm{~g}$ & $1,75 f$ & UFRGS66F & $83,97 \mathrm{e}$ & $1,64 \mathrm{f}$ \\
\hline UFRGS 28F & $21,09 \mathrm{~h}$ & $2,71 \mathrm{f}$ & UFRGS67F & 157,44 c & 9,07 a \\
\hline UFRGS 29F & $35,92 \mathrm{~g}$ & $2,86 \mathrm{e}$ & UFRGS68F & 158,05 c & $5,85 \mathrm{c}$ \\
\hline UFRGS 30F & $20,65 \mathrm{~h}$ & $1,69 f$ & UFRGS69F & $66,45 \mathrm{f}$ & 3,46 e \\
\hline UFRGS 31F & $24,65 \mathrm{~g}$ & $1,63 f$ & UFRGS70F & $71,94 \mathrm{f}$ & $1,79 \mathrm{f}$ \\
\hline UFRGS 32F & $13,44 \mathrm{~h}$ & $0,80 \mathrm{f}$ & UFRGS71F & 61,98 & 5,03 \\
\hline UFRGS 33F & $10,50 \mathrm{~h}$ & $1,63 f$ & UFRGS72F & 66,99 & 1,58 \\
\hline UFRGS 34F & $36,75 \mathrm{~g}$ & $0,80 \mathrm{f}$ & UFRGS73F & 63,07 & 3,39 \\
\hline UFRGS 35F & $72,18 \mathrm{f}$ & $5,66 c$ & UFRGS74F & 86,71 & 10,7 \\
\hline UFRGS 36F & $69,93 \mathrm{f}$ & $8,84 a$ & UFRGS75F & 172,67 & 6,51 \\
\hline UFRGS 37F & 97,28 e & $8,84 a$ & UFRGS76F & 53,55 & 9,48 \\
\hline UFRGS 38F & $78,28 \mathrm{e}$ & $8,21 \mathrm{~b}$ & Sp7 & 102,47 & 1,57 \\
\hline UFRGS 39F & $82,73 e$ & 3,35 e & CV(\%) & 13,3 & 19,21 \\
\hline
\end{tabular}

Médias seguidas da mesma letra na coluna não diferem significativamente entre isolados pelo teste de Scott-Knott a 5\% de probabilidade de erro.

proteína $^{-1}$ (isolado UFRGS74F). Os maiores valores foram obtidos pelos isolados UFRGS74F, UFRGS16F, UFRGS36F, UFRGS37F, UFRGS46F, UFRGS47F, UFRGS48F e UFRGS56F, UFRGS67F e UFRGS76F. Estudando a produção de AIA de diversas espécies de bactérias diazotróficas, PEDRAZA et al. (2004) verificaram que a produção das bactérias incubadas sob agitação de $90 \mathrm{~g}$ por $72 \mathrm{~h}$, em caldo nutritivo, variou de 4,37 a 27,32 $\mu$ g AIA mg proteína ${ }^{-1}$. A maior produção foi obtida pelo isolado pertencente à espécie $\boldsymbol{A}$. brasilense.

Os resultados de produção de AIA e N fixado pelos isolados demonstram que estes dois eventos não se inter-relacionaram (Tabela 3). Estes

Ciência Rural, v.37, n.3, mai-jun, 2007. 
resultados mostram-se coerentes, pois se sabe que estes processos são independentes, por serem codificados por genes distintos. Estudando a estirpe Azospirillum OAD-57, GADAGI et al. (2004) verificaram que houve correlação negativa entre a produção de PCPs e $\mathrm{N}$ fixado, já que a estirpe produziu grande quantidade de PCPs, porém fixou pequena quantidade de N.

O desempenho dos microrganismos foi quantificado in vitro, sugerindo que o próximo passo neste estudo seria avaliar o potencial dos isolados in situ para verificar sua competitividade em campo, pois a colonização e o estabelecimento destes microrganismos associativos são influenciados de maneira diferente, dependendo das populações naturais do solo (BALDANI et al., 1986).

\section{CONCLUSÕES}

Bactérias diazotróficas ocorrem em associação com plantas de sorgo forrageiro. A diversidade das bactérias diazotróficas foi influenciada pelos genótipos de sorgo. As bactérias isoladas foram aptas em fixar $\mathrm{N}_{2}$ e produzir ácido indol-acético in vitro.

\section{REFERÊNCIAS}

BALDANI, V.L.D.; DÖBEREINER, J. Host-plant specificity in the infection of cereals with Azospirillum spp. Soil Biology and Biochemistry, Oxford, v.12, n.4, p.433-439, 1980.

BALDANI, J.I. et al. Characterization of Herbaspirillum seropedicae gen. Nov., sp. Nov., a root associated nitrogen fixing bacterium. International Journal of Systematic Bacteriology, Washington, v.36, n.1, p.86-93, 1986.

BASHAN, Y. et al. Azospirillum - plant relationships: physiological, molecular, agricultural, and environmental advances (1997-2003). Canadian Journal of Microbiology, Ottawa, v.50, p.521-577, 2004.

BODDEY, R.M. et al. Biological nitrogen fixation associated with sugar cane. Plant and soil, Dordrecht, v.137, n.1, p.111117, 1991.

BRADFORD, M.M. A rapid and sensitive method for the quantitation microgram quantities of protein utilizing the principle of protein-dye binding. Analytical Biochemistry, New York, v.72, p.248-254, 1976.

CHIARINI, L. et al. Inoculation of Burkholderia cepacia, Pseudomonas fluorescens and Enterobacter sp. on Sorghum bicolor: Root colonization and plant growth promotion of dual strain inocula. Soil Biology and Biochemmistry, Oxford, v.30, n.1, p.81-87, 1998

COMISSÃO DE FERTILIDADE DO SOLO - RS/SC Recomendações de adubação e calagem para os estados do Rio Grande do Sul e de Santa Catarina. 3.ed. Passo Fundo: SBCS - Núcleo Regional Sul, 1995. 394p.

DÖBEREINER, J. et al. Como isolar e identificar bactérias diazotróficas de plantas não leguminosas. Brasília: Embrapa-SP, 1995. 60p.

EMBRAPA. Centro Nacional de Pesquisa de Solos. Sistema Brasileiro de classificação de solos. Brasilia: SPI, 1999. 412p.

FERNANDES, V.L.B. et al. Absorção e utilização de nitrogênio em planta de sorgo cultivado em solução nutritiva. Ciência Agronômica, Fortaleza, v.22, n.1/2, p.89-96, 1991

GADAGI, R.S. et al. The effect of combined Azospirillum inoculation and nitrogen fertilizer on plant growth promotion and yield response of the blanket flower Gaillardia pulchella. Scientia Horticulturae, Amsterdam, v.100, p.323-332, 2004.

GRAYSTON, S.J. et al. Selective influence of plant species on microbial diversity in the rizosphere. Soil Biology and Biochemistry, Oxford, v.30, n.3, p.369-378, 1998.

KIPE-NOLT, J.A. et al. Root exudation of sorghum and utilization of exudates by nitrogen-fixing bacteria. Soil Biology and Biochemistry, Oxford, v.17, n.6, p.859-863, 1985.

PEDRAZA, R.O. et al. Aromatic amino acid aminotransferase activity and indole-3-acetic production by associative nitrogenfixing bacteria. FEMS Microbiology Letters, Amsterdam, v.233, p.15-21, 2004.

STEIN, T. et al. Contribution of BNF by Azoarcus sp. BH72 in Sorghum vulgare. Soil Biology and Biochemistry, Oxford, v.29, n.5/6, p.969-971, 1997.

TEDESCO, M.J. et al. Análise de solo, plantas e outros materiais. 2.ed. Porto Alegre: Depto. de Solos da UFRGS, 1995. 174p. 